\title{
Natural Compounds and Depressive Disorder: A Review Highlighting Botanical Sources and Reaction Mechanisms
}

\author{
LING Jia ${ }^{1 \#}$, HAN Yuanshan ${ }^{2 \#}$, MENG Pan ${ }^{1,3}$, LIU Jian² ${ }^{2}$ ZHAO Hongqing ${ }^{1,3}$, WANG Yuhong ${ }^{1,3 *}$ and LI \\ Shunxiang ${ }^{3,4 *}$ \\ ${ }^{1}$ Institute of Innovation and Applied Research in Chinese Medicine, Hunan University of Chinese Medicine, China \\ ${ }^{2}$ First Hospital of Hunan University of Chinese Medicine, China \\ ${ }^{3}$ State Key Laboratory of Chinese Medicine Powder and Medicine Innovation in Hunan, Hunan University of Chinese Medicine, China \\ ${ }^{4}$ School of Pharmacy, Hunan University of Chinese Medicine, China \\ ${ }^{\#}$ Both authors are equally contributed
}

*Corresponding author: WANG Yuhong, Institute of Invocation and Applied Research in Chinese Medicine, Hunan University of

Chinese Medicine, 300 Xueshi Road, Hanpu Science \& Education District, Changsha City, Hunan Province, PR China

Li Shunxiang, School of Pharmacy, Hunan University of Chinese Medicine, Changsha City, Hunan Province, PR China

ARTICLE INFO

Received: 㹃 October 18, 2021

Published: 慧 December 06, 2021

Citation: LING Jia, HAN Yuanshan, MENG Pan, WANG Yuhong, LI Shunxiang, et al., Natural Compounds and Depressive Disorder: A Review Highlighting Botanical Sources and Reaction Mechanisms. Biomed J Sci \& Tech Res 40(3)-2021. BJSTR. MS.ID.006446.

Keywords: Depressive Disorder; Natural Compounds; Reaction Mechanism; TCM

\section{ABSTRACT}

Depressive disorder is a typical mental illness characterized by depressed mood and anhedonia, with a great burden to patients and society. Currently, only a small minority of medicines are efficient in the clinic with high prices and various adverse reactions, including sleep disorders and gastrointestinal reactions. To develop new antidepressants, pharmacists have gradually turned their attention to phytochemicals, especially those from traditional Chinese medicine (TCM). Natural products could be good candidates for developing effective drugs and valid therapeutic strategies. In this article, we reviewed more than 20 natural compounds from TCMs with protective action against the depressive disorder, and their reaction mechanisms were reviewed from four aspects: reversing neurotransmitter imbalance, maintaining neuroendocrine homeostasis, alleviating synaptic plasticity dysfunction, and inhibiting neuroinflammation.

Abbreviations: TCM: Traditional Chinese Medicine; NR3C1: Nuclear Receptor Subfamily 3 Group C Member 1; GRIN2A: Glutamate Ionotropic Receptor NMDA Type Subunit 2A; CUMS: Chronic Unpredictable Mild Stress; SDS: Social Defeat Stress; LH: Learned Helplessness; CRS: Chronic Restraint Stress; HPA: Hypothalamic-PituitaryAdrenal; OVX: Ovariectomized; OB: Olfactory Bulbectomy; MCAO: Middle Cerebral Artery Occlusion; TCA: Tricyclic Antidepressants; SSRI: Selective Serotonin Reuptake Inhibitors; NSMRI: Selective Monoamine Reuptake Inhibitors; MAOI: Monoamine Oxidase Inhibitors 5-HT: 5-Hydroxytryptamine; NE: Norepinephrine; MAOI: Monoamine Oxidase Inhibitor; GluR: 5-HIAA Ionotropic Glutamate Receptors; mGluR: Metabotropic Glutamate Receptors; NMDAR: N-Methyl-D-Aspartate Receptor; AMPAR: A - Amino-3-Hydroxy-5-Methyl-4-Isoxazol-Propionic Acid Receptor; GABA: GammaAmino Butyric Acid; CCI: Chronic Constriction Injury; 4-AP: 4-Aminopyridine; M1-AChR: M1-Type Muscarinic Acetylcholine Receptors; HPT: Hypothalamic-Pituitary-Thyroid; HPG: Hypothalamicpituitary-Gonad; BBB: Blood Brain Barrier; Cx43: Connexin43; BDNF: Brain-Derived Neurotrophic Factor; TrkB: Tyrosine Kinase Receptor B; KYN: Kynurenine; DG: Dentate Gyrus; LTP: Long-Term Potentiation; NSCs: Neural Stem Cells; NSAIDs: Non-Steroidal Anti-Inflammatory Drugs; iNOS: Nitric Oxide Synthase; DHM: Dihydromyricetin; p-ERK1/2: Phosphorylated Extracellular Signal-Regulated Kinase 1/2; WKY: Wistar-Kyoto 


\section{Introduction}

\section{Etiology of Depressive Disorder}

Depressive disorder is a recurrent serious neuropsychiatric disease, with an incidence of up to $17 \%[1,2]$. What's more, the direct or indirect cost of the depressive disorder has reached US\$2.5 trillion and is expected to exceed US\$6 trillion by 2030 . Approximately 1,000,000 people die of suicide every year around the world [3,4], and more than $90 \%$ of them have been diagnosed with depression or other mood disorders [5]. In general, depression brings tremendous social and economic burdens, as well as a gigantic adverse effect on social activities and family responsibilities. As a complex multifactor disease, depressive disorder is initiated and triggered by psychological, genetic, social, and biological factors. Increasing evidence shows that the occurrence and development of depression are closely related to genetic factors, and depression is a highly inherited disease, with $40 \%-50 \%$ of its risk coming from genes [6]. Multiple genes such as Nuclear receptor subfamily 3 group C member 1 (NR3C1), glutamate ionotropic receptor NMDA type subunit 2A (GRIN2A), and many others are closely related to depression outcome $[7,8]$. Psychological factors contain abuse (including sexual, physical, or emotional), psychological neglect, exposure to violence, separation, and bereavement, and so on. Social factors, such as chronic health problems, exposure to violence, financial insecurity, are strongly associated with the risk of developing depressive disorder. Biologically speaking, periodic changes of hormones and long-term health problems can also contribute to the occurrence of depression, such as postpartum depression and diabetic depression.

\section{Animal Models of Depressive Disorder}

Due to the complex pathogenic factors and the high comorbidity rate with other mental diseases (such as anxiety, phobia, schizophrenia, etc.), it is difficult to maintain a strict boundary between depression and other mental diseases, and the animal models of depression are essential to understand the pathological mechanism [9]. Presently, rats (Sprague-Dawley rats, Wistar rats), mice (C57BL/6 mice, ICR mice, Kunming mice), non-human primates (rhesus monkeys, cynomolgus monkeys, etc.), zebrafish, tree shrew are common model animals for the preclinical study of depression. In the aspect of animal modeling, stress exposure is the most common molding method, because it can simulate the clinical disease process of humans to the greatest extent, including chronic unpredictable mild stress (CUMS) [10,11], social defeat stress(SDS) [11,12], learned helplessness (LH), chronic restraint stress (CRS). On the other hand, some depressive animal models were set up guided by the corresponding hypothesis, such as injection of lipopolysaccharide (inducing inflammation) [13], corticosterone (destructing HPA axis) [14,15], and reserpine (exhausting monoamine transmitter) [16,17]. Besides, surgical models are also good choices to establish a depression model, including ovariectomized (OVX), olfactory bulbectomy (OB), and middle cerebral artery occlusion (MCAO). Despite multiple modeling methods, CUMS is the most classical and widespread one.

\section{Intervention in Depressive Disorder}

Presently, the commonly prescribed antidepressants have been divided into four categories, including tricyclic antidepressants (TCA), selective serotonin reuptake inhibitors (SSRI), non-selective monoamine reuptake inhibitors (NSMRI), and monoamine oxidase inhibitors (MAOI) [18]. However, conventional antidepressants lack efficacy in many patients (treatment-resistant depression), and combined medication (multitherapy) and several weeks were required to produce a therapeutic response in about $50 \%$ of depression cases $[19,20]$. Besides, there is also increasing evidence in terms of serious side effects of antidepressants, such as cognitive impairments, arrhythmias, sleep disorders, and gastrointestinal reactions. For example, fluoxetine is one of the most common antidepressants worldwide, while it also induces many side effects such as hepatotoxicity and gastrointestinal reaction [22]. Thus, these disadvantages of antidepressants may limit clinical use and are not directly conducive to the treatment of depression. Psychotherapy is a common treatment program for depression, but it does not demonstrate outstanding superiority compared with control [23]. Likewise, Cochrane reviews that the evidence of other alternative therapies, such as acupuncture and exercise, are short of persuasiveness and convincing [24,25]. Therefore, current researchers are devoted to the search and development of novel effective drugs with high efficacy and low side-effects during the past two decades [26,27]. Traditional Chinese medicine has unique advantages in prolonging the human life span, improving the quality of life, and preventing and treating chronic diseases, including diabetes, cancer, and depressive disorder.

\section{Materials and Methods}

We searched the relevant experimental articles published from October 2014 to July 2021 in the PUBMED database to clarify the antidepressant effects of natural compounds. Our search statement is designed according to the following criteria: the search language contains relevant keywords such as 'depressive disorder' and 'natural product' or compounds category, including alkaloids, flavonoids, polyphenols, phenylpropanoids, polyphenols, and quinones. After completing the preliminary search, duplicated or non-English articles, as well as studies involving natural products of multiple compounds such as extracts were deleted, and the literature on single compounds was retained so that we could completely comprehend how each natural compound exerts antidepressant effects and their potential mechanism. 


\section{Results}

\section{Natural Compounds that Restore Neurotransmitter Imbalance}

Neurotransmitters are messengers of information exchange between neurons or between neurons and effector cells such as muscle cells, glandular cells, etc., including monoamines (norepinephrine, dopamine, and serotonin), amino acids (excitatory transmitters such as glutamic acid and aspartic acid; inhibitory transmitters such as $\gamma$-aminobutyric acid, glycine, and taurine), choline (acetylcholine) and others, such as neuropeptides and purines [28]. In this section, plant chemicals and/or extracts are listed according to their impacts on neurotransmitters Their chemical structures, antidepressant activities, and action on restoring neurotransmitter imbalance in animal models of depression are discussed.

\section{Natural Compounds Regulating Monoamine} Neurotransmitters and Related Receptors: Among all of the neurotransmitters, monoamine neurotransmitters are most closely related to depression, and valid antidepressant drugs are mainly designed to target the monoamine neurotransmitter system, including the serotonergic and noradrenergic systems. Currently, the monoamine transmitter hypothesis believes that the concentration of brain neurotransmitters in the synaptic gap is relatively or absolutely insufficient, which will lead to overall mental activity and mental function in a comprehensive state of depression [29]. Clinical studies have found that 5-hydroxytryptamine (5-HT) and norepinephrine (NE) are insufficient in the brain of depressed patients, while antidepressants can exert effects by inhibiting the reuptake of these two neurotransmitters and increasing the concentration of transmitters in the synaptic gap [30,31].

Ferulic Acid: Ferulic acid, or 4-hydroxy-3-methoxy-cinnamic acid, is derived from Umbelliferae family TCM plants, such as Ferulae Resina (e'wei, 阿魏), Angelicae Sinensis Radix (danggui, 当归), Aconiti Radix (chuanxiong, 川芦), Cimicifugae Rhizoma (shengma, 升麻), and Ziziphi Spinosae Semen (suanzaoren, 酸柊仁). As a polyphenol compound, ferulic acid has good blood-brain barrier permeability [32]. Many studies have shown that ferulic acid may be an MAOI antidepressant, suggesting that ferulic acid selectively increases the levels of serotonin and norepinephrine in the various brain to alleviate depression [33,34]. Moreover, the inhibitors of 5-HT1A/5-HT2A receptors can clear up the antidepressant activity of ferulic acid [35]. Furthermore, Li G, et al. [36] performed that the administration of ferulic acid exerts obvious antidepressant effects by reducing MAO-A activity and 5-HIAA content, which suggested that ferulic acid, combined with a low dose of piperine, may be a potential therapeutic method of depression with high efficacy and low side effects.
Naringenin: Naringenin is a special flavonoid widely distributed in various Chinese Medicine for antidepressants, such as Menthea haplocalycis herba (bohe, 薄荷) and Auranrii fractus (zhiqiao, 枳壳). Compared with other flavonoids, it is more easily to be absorbed by the gastrointestinal tract, with high bioavailability and high safety dose [37,38]. Mounting evidence shows that naringenin is a potential antidepressant [39-44]. On the one hand, it can increase the 5-HT level by inhibiting MAO [45] or regulating the metabolic process of tryptophan $[39,41]$. Another, it exerts a neuroprotective role through the sonic hedgehog-Gli1 signaling pathway and restores alterations in the kynurenine (KYN) pathway via its antioxidant and anti-inflammatory potential [40,42].

Umbelliferone: Umbelliferone, or 7-hydroxycoumarin, is one of the coumarin derivatives. Many effects have been documented for this compound ranging from anti-oxidation, anti-inflammatory, and neuroprotection. As for depression, this compound can significantly improve CUMS-induced depressive behaviors, including lack of pleasure and prolonged immobility. It can inhibit the activity of MAO and lower the elimination of 5-HT [46]. Interestingly, many of its derivatives also are good MAO inhibitors [47]. Besides, umbelliferone can inhibit neuronal apoptosis via modulating the ROCK/Akt pathway or GSK-3 $\beta /$ PI3K/Akt pathway to treating depression $[48,49]$.

Chrysin: Chrysin is a kind of flavonoid extracted from the plant of Oroxyli semen (muhudie, 木蝴蝶) or propolis, with extensive pharmacological activity, including strong neuroprotective and anti-inflammation effects [50]. And it is potent for depression caused by different reasons, such as ovariectomy, hypothyroidism, CUMS, traumatic brain injury, and olfactory bulbectomy [50-58]. Chrysin can not only increase the level of BDNF [51,57] and other neurotrophic factors, but also regulate the level of 5-HT and its production and metabolism $[54,55,57,58]$.

Natural Compounds that Regulate Amino Acid Neurotransmitters and their Receptors: Amino acid neurotransmitters include excitatory transmitters (e.g. glutamate and aspartic acid) and inhibitory transmitters (e.g. $\gamma$-aminobutyric acid, glycine, and taurine). Growing evidence demonstrates that glutamatergic transmission may be the critical cause of depression occurrence, though the imbalance of monoamine neurotransmitters is the classic pathogenesis of depression [59]. Both clinical and preclinical results show that depression is closely related to the increase in glutamate concentration [60]. The receptors of glutamate are divided into ionotropic glutamate receptors (GluR) and metabotropic glutamate receptors (mGluR). The former includes N-methyl-D-aspartate receptor (NMDAR), $\alpha$ - amino-3-hydroxy-5-methyl-4-isoxazol-propionic acid receptor (AMPAR), and kainate receptor family, while the latter belongs 
to $\mathrm{G}$ protein-coupled receptors and involves eight subtypes, mGluR1 8. Previous studies have indicated that NMDAR, AMPAR, and mGluR $(1 / 2 / 3 / 5)$ are closely related to depression [61,62]. However, lowering inhibitory transmitters GABA, also known as $\gamma$-aminobutyric acid, is associated with depression, and GABA regulates local neural circuits including norepinephrine, dopamine, and serotonin neurons $[59,63]$. Therefore, the balance between glutamate and GABA is considered one of the key points in the pathogenesis of depression.

Curcumin: Curcumin is a polyphenol component extracted from Zingiberaceae and Araceae family, and the typical TCMs include Wenyujin Rhizoma Concisum (jianghuang, 姜黄), Curcumae Radix (yujin, 郁金), and Curcumae Rhizzoma (e'zhu, 莪术). Multiple functions have been reported for this agent, including lipid regulation, inflammation inhibition, and tumor suppression. As for depression, this compound can normalize the depressive behaviors in lipopolysaccharide-induced and chronic constriction injury (CCI) model mice [64-66]. And above ant depression was greatly eliminated by GABA receptor A antagonist bicuculline, but only partly abrogated by 5 -HT receptor $1 \mathrm{~A}$ antagonist [65]. Similarly, Ro25-6981 (GluN2B antagonist) was found to prevent the pharmacodynamics function of curcumin in FST [64]. From another perspective, curcumin can inhibit glutamate release from synaptosomes induced by 4-aminopyridine (4-AP), a $\mathrm{K}^{+}$channel blocker, which can be completely abolished by fluoxetine, a clinically effective antidepressant [67]. Thus, the antidepressant effect of curcumin may be mediated, at least in part, by regulating the balance between glutamate and GABA.

\section{Natural Compounds that Regulate Cholinergic} Neurotransmitters and their Receptors: The cholinergic system plays a significant role in regulating various CNS functions, including arousal, attention, cognition, and memory, and the abnormality of the cholinergic system is associated with depression. Although the role of the cholinergic system in the pathogenesis of depression is not as widely accepted as the monoamine hypothesis, it has been proposed decades ago. Recent studies have shown that increasing the activity of the cholinergic system shortly before stress induction can affect the ability to cope with forthcoming stress, bringing about depression-like conditions [68,69].

Scopolamine: Scopolamine, separated from nightshade family plant Dature Stramonium Datura $L$, is a nonselective muscarinic antagonist, especially for M1-type muscarinic acetylcholine receptors (M1-AChR); and its main effects are used to treat motion sickness and nausea, but growing studies have revealed that scopolamine posts a rapid antidepressant activity in humans and animals, and maybe a promising antidepressant agent or adjuvant. However, its antidepressant activity can be eliminated by M1-AchR knockout [70], AZD8055 (an orally-bioavailable mTOR inhibitor) [71], AMPT (a tyrosine hydroxylase inhibitor) [72], NBQX (an inhibitor of AMPAR) [73], or VGLUT1 knockdown [74]. Overall, these results indicate that although scopolamine is a muscarinic antagonist, its antidepressant effect in animal depression models is related to not only the cholinergic system but also to noradrenergic and glutamic acid systems and the mTOR pathway.

\section{Natural Compounds that Maintain Neuroendocrine Homeostasis}

The endocrine system is another important functional regulation system besides the nervous system, and the main endocrine organs include the pituitary gland, thyroid gland, adrenal gland, islet of the pancreas, and gonad. Especially, the hypothalamus cannot only regulate nerve function, but also measure endocrine function, and there are three important neuroendocrine axes, including the HPA axis, HPT axis, and HPG axis. Among these, the HPA axis is an important neuroendocrine system for the human body to cope with stress. When individuals are faced with stressors, they can increase hormone levels in a series of ways, causing the human body to produce a stress response.

Ginsenoside Rg1: Ginsenoside $\operatorname{Rg} 1$ is one of the most active components in ginseng radix et rhizoma (renshen, 人参), which has a variety of biological activities, including promoting neurogenesis and neural plasticity, enhancing learn and memory, and improving immunity. Therefore, this compound may have great potential in the treatment of depression. Several studies have proved that ginsenoside $\operatorname{Rg} 1$ significantly alleviates depressive behaviors induced by CUMS, CSDS, or corticosterone [75-79]. It has been shown that ginsenoside $\mathrm{Rg} 1$ can protect the function of gap junction to repair the integrity of blood-brain barrier (BBB) and connexin 43 ( $\mathrm{Cx} 43)$ is the key sensitive target [80-82]. Moreover, it also can reduce dendritic spine atrophy and modulate the homeostasis of the HPA and HPG axis [83].

Puerarin: Puerarin is a kind of isoflavone derivative isolated from TCM, Pueraria lobata (gegen, 葛根), and is also the main pharmacological component. Its main effects are to dilate blood vessels and improve microcirculation, so it is often used in the treatment of hypertension and coronary artery disease [84]. However, recent researchers have found puerarin may be a potential antidepressant, due to its neurotrophic and estrogenlike effects [85-87]. Of note, it has been reported that puerarin shows a significant antidepressant effect on ovariectomized ICR mice, including behavioral remission and corticosterone reduction [87]. Further, puerarin also dose-dependently normalized the downregulated transcription of estrogen receptor $(\operatorname{Er} \beta$ and Er $\alpha$ ) and BDNF mRNAs [87]. On the other hand, puerarin plays a biological role in the synthesis of allopregnanolone in the brain [88]. In summary, puerarin exerts antidepressant effects directly through its estrogen-like effect, or indirectly through promoting the biosynthesis of estrogen. 
Hyperforin and Hyperoside: Hypericum perforatum (guanyejinsitao, 贯叶金丝桃), namely St John's wort, is a classic antidepressant plant drug. Hyperforin and hyperoside are its main active components, and even have been regarded as the quality control index. Due to their significant efficacy and small side effects, they have become the first choice for the treatment of depression in Europe and the United State. Previous evidence has shown that the two compounds can inhibit the activity of MAO and the synaptosomal reuptake of monoamine [89]. However, recent studies show that hyperforin can activate TRPC6-mediated currents and $\mathrm{Ca}^{2+}$ transients to modulate synaptic plasticity in rat PC12 cells, and change BDNF and zinc levels in mice exposed to CUMS to exert significant antidepressant-like activity $[90,91]$. Similarly, hyperoside protects rats from CMS-induced learning and memory deficits, while these effects could be prevented by K252a, an inhibitor of the BDNF receptor tyrosine kinase receptor B (TrkB) [92]. Therefore, hyperforin and hyperoside can recovery the synaptic function to treat depressive disorder.

Hesperidin: Hesperidin is the main active component of TCM from the Rutaceae family, including Citri reticulatae pericarpium (chenpi, 陈皮), Auranrii fractus (zhiqiao, 枳壳), and Citri sarcodactylis fructus (foshou, 佛手), which are related to soothing the liver and relieving depression. Hesperidin has been reported to exhibit a beneficial effect on various depressive animals, and alleviating neuroinflammation may be the key mechanism of efficacy [92,93]. It has been reported that this phytochemical could not only inhibit the increase of KYN level in the prefrontal cortex of CSDs rats, but also antagonize the downregulation of miRNA-132 expression in lipopolysaccharide-induced depression mice [94,95]. Moreover, hesperidin reduces inflammatory cytokine levels by modulating the HMGB1/RAGE/NF-kB pathway and the BDNF/TrkB pathway both in vivo and in vitro [96]. Thus, hesperidin may be a potential antidepressant candidate.

Paeoniflorin: Paeoniflorin, exacted from Paeoniae root, is the principal bioactive ingredient of Paeoniae radix rubra (chishao, 赤 芶) and Paeoniae radix alba (baishao, 白芶). Due to its low toxicity, there is no obvious adverse reaction under normal conditions. A large number of studies have proved that paeoniflorin has many pharmacological effects, including antidepressants, analgesics, liver protection, nerve protection, and immune regulation. Regarding depression treatment, paeoniflorin has a very significant therapeutic effect. This chemistry can promote neurogenesis in the hippocampal dentate gyrus (DG) and attenuate impairment of longterm potentiation (LTP) in hippocampal CA1 of animals subjected to CUMS [97-99]. Mechanically, the activation of the ERK/CREB pathway may be the internal reason for its antidepressant effect. On the other hand, paeoniflorin can also play a protective role in neurons through calcium antagonism $[100,101]$.

\section{Natural Compounds that Relieve Neurological and Synaptic Dysfunction}

Synapse is the basic structure between neurons for information transmission and processing. Synaptic plasticity refers to the adaptive changes of the brain to stimulation, including structural and functional changes, which are manifested in the increase or decrease of the synaptic number, the change of synaptic morphology, and the adjustment of synaptic function. Peripheral inflammation and synaptic abnormalities are thought to directly or indirectly induce brain functional abnormalities contributing to depression $[102,103]$, and the change of synaptic plasticity has become one of the key indicators in the treatment of depression.

Asiaticoside: Asiaticoside, the main active ingredient in Centellae herba (jixuecao, 积雪草), has many pharmacological activities, including regulating immunization, anti-inflammatory and promoting wound healing [104]. Luo, L et al. [105] found that asiaticoside poses a significant antidepressant action in CUMS-exposed mice through activating BDNF signaling in the hippocampus, which could be totally eliminated by K252a, a BDNF receptor inhibitor. Furthermore, asiaticoside was able to reverse the inflammation and the PKA/pCREB/BDNF signaling pathway to play an antidepressant effect [106].

Harmine: Harmine, a confirmed MAO inhibitor, is a natural $\beta$-carboline alkaloid extracted from Peganum harmala $L$ (luotuopeng, 骆驼蓬) used by Mongolian doctors and is considered a potential antidepressant. It was reported that harmine treatment $(20 \mathrm{mg} / \mathrm{kg}$ ) decreases the immobility in TST and FST, and increases the sucrose intake in SPT, and prevents reductions of BDNF, GLT1, and GFAP in the hippocampus induced by CUS [107]. Besides, its antidepressant effects were able to eliminate by l-AlphaAminoadipic Acid, gliotoxin specific for astrocytes, which means harmine was an effective therapeutic agent via the restoration of astrocytic dysfunctions [108]. However, a study certified that harmine (15 mg/kg, i.p.) has no effects on RSD-induced acute depressive behavior, or even caused some unpredicted side effects, such as severe weight loss and reduced locomotion on open field tests [109].

Silymarin: Silymarin is a flavonoid mixture composed of silybin, isosilybim, silydianin and silychristin, which are extracted from Silybi fructus (shuifeij, 水飞蓟). Concerning antidepressants, silymarin has a distinct effect on olfactory bulbectomized (OBX) mice and CUMS mice [110,111]. These compounds were also shown to improve the proliferation of neural stem cells (NSCs), promote phosphorylation of ERK and CREB, as well as modulate the expression of BDNF and TrkB, while the above efficacy of silibinin is neutralized by TrkB antagonist, GNF5837 [112]. 
Baicalin: Baicalin, the main active component of Scutellariae radix (huangqin, 黄芩), has a variety of pharmacological effects, such as antibacterial, diuretic, anti-inflammatory, cholesterol lowering, antithrombotic, and so on [113]. Meanwhile, generous evidence shows that baicalin has a good therapeutic effect on depressive animals. On CUMS mice, baicalin can regulate the NMDAR/NR2B-ERK1/2-related pathway to ameliorate behavioral performance and reduce cytokines levels [114]. Differently, this compound can reduce the serum level of corticosterone on depression mice induced by 21-day corticosterone injection, and increase the expression of BDNF in the hippocampus by GR/SGK-1/ BDNF pathway [115]. Other, baicalin exert obvious antidepressant activity on rat induced by OBX, and its core mechanism is related to anti-oxidation and anti apoptosis [116].

Paeonol: Paeonol is an effective component extracted from the Moutan cortex (mudanpi, 牡丹皮), which has prominent effects on analgesia, anti-inflammation, antipyretic and anti-allergic reactions. This agent has been shown to attenuate lipopolysaccharideinduced depressive-like behavior in mice [117]. Furthermore, it also affects CUMS-induced rats. After Paeonol application for 4 weeks, the length and density of dendritic spines in hippocampal CA1 and dentate gyrus (DG) were considerably increased, while the expression of Rac1/RhoA was upregulated [118]. These results suggested that paeonol could restore synaptic plasticity through the BDNF-Rac1/RhoA pathway to an anti-depressant.

\section{Neuroinflammation Reaction}

Depression is accompanied by the up-regulation of inflammatory factors, such as IL-1 $\beta$, IL-6 and TNF- $\alpha$. Meanwhile, anti-inflammatory agents such as non-steroidal anti-inflammatory drugs (NSAIDs), inflammatory factor inhibitors, and statins can improve the behavioral score of depressive patients by improving neuroinflammation [119,120]. Additionally, some inflammatory factors, such as CRP, IL- 6 , and TNF- $\alpha$, can be used as biomarkers of depression [121]. Microglia and astrocytes are also found to be activated in the brain of depressed mice [122]. Therefore, neuroinflammation may be the key pathogenesis of depressive disorder. In this section, we discuss the compounds and/or extracts that exert anti-neuroinflammation activities in microglia and/or depressive animal models.

Sinomenine: Sinomenine is a monomeric alkaloid that can be extracted from Chinese traditional medicine Sinomenii caulis (qingfengteng, 青风藤). Multifold effects have been reported for this chemistry ranging from pain relief, inflammatory inhibition, and immunologic suppression [123]. Sinomenine has also be shown a significant anti-depressant effect on depressive animals treated by CSDS or CUMS $[124,125]$. It can reduce the levels of IL-1 $\beta$, IL-6, and TNF- $\alpha$ in the hippocampus of mice, by preventing NF-KB pathway and NLRP3 inflammasome activation. Therefore, sinomenine may be a promising and effective drug for depression.

Berberine: Berberine is the main component of the Chinese herb Coptidis rhizoma (huanglian, 黄连) with many pharmacological effects, such as anti-inflammatory, antiviral, anti-arrhythmia and antihypertension [126]. Differently, berberine has been documented to exhibit a favorable effect on neuroinflammation suppression [127]. It can decline the expression of pro-inflammatory cytokines (IL-1 $\beta$, IL-6, and TNF- $\alpha$ ), and inhibit microglial activation and NF$\kappa B$ signaling pathway, including ІкB kinase (IKK) $\alpha$, IKK $\beta$ and nitric oxide synthase (iNOS), in the hippocampus. Moreover, another recent study shows that oral administration of berberine $(150 \mathrm{mg} /$ $\mathrm{kg}$ ) could increase consumption of sugar water in SPT, upregulate the expression of BDNF, GR, CREB, and NADH dehydrogenase, such as Ndufb $(4,5,6)$, Ndufa $(6,7)$, and Ndufs4, et.al., which suggests that berberine is a potential antidepressant via ameliorating mitochondrial energy [128].

Dihydromyricetin: Dihydromyricetin (DHM), one type of flavonoid natural product isolated from Semen hoveniae (zhijuzi, 枳椇子), has a rapid antidepressant-like effect by activating the ERK1/2-CREB pathway. Ren Z, et al. [129] have found seven days of DHM treatment declined immobility time in the TST and FST both in normal mice and the lipopolysaccharide-induced acute depressive mice, and increased glycogen synthase kinase- 3 beta (GSK-3 $\beta$ ) phosphorylation, with the increase of BDNF expression, both in vivo and in vitro. Additionally, Guan S, et al. [130] studied that DHM could relieve diabetic depressive disorder, as indicated by a series of behavioral tests, such as SPT, FST, and OFT, and the mechanism may be through reducing the expression of the P2X7 receptor which is a member of the ATP-gated ion channel family, phosphorylated extracellular signal-regulated kinase $1 / 2(\mathrm{p}$-ERK1/2), TNF- $\alpha$, and IL-1ß in the DRGs, spinal cord, and hippocampus.

Icariin: Icariin, a flavonoid isolated from the Chinese herb Epimedii folium (yinyanghuo, 淫羊藿), can penetrate the bloodbrain barrier to play an anti-inflammatory and antioxidant role in CNS [131]. Moreover, it has been shown to decline depressive disorder in CMS-treated animals [132]. This decline covered inflammatory mediators (TNF- $\alpha, \mathrm{IL}-1 \beta$, and NF- $\mathrm{kB}$ ) and oxidativenitrosative stress markers (MDA, SOD, CAT, and iNOS) in CMS rats' hippocampus. Importantly, icariin can inhibit microglial activation and regulate the NLRP3-inflammasome/caspase-1/IL-1 $\beta$ axis [133]. On the other hand, icariin also can regulate the expression of mGluR1, mGluR5, and EAAT2 in the hippocampus to ameliorate depression induced by prenatal restraint stress [134].

Apigenin: Apigenin is widely distributed in tropical vegetables and fruits, especially in celery or Apii herba (hanqin, 旱芹). Many studies $[135,136]$ have reported that apigenin relieved depressive 
behavior induced by CUMS in rats. This fraction sharply lessens the production of IL-1 $\beta$ and IL-18, with balancing oxidation markers (GSH and MDA) in PFC [137]. Particularly, apigenin can up-regulate the expression of PPARy to reduce NLRP3 inflammasome, and its antidepressant effect can be neutralized by GW9662, a selective PPARy inhibitor [137], which suggests that PPARy may be the crucial target for apigenin to exert antidepressant efficiency.

Fisetin: Fisetin, a type of small-molecule flavonoid, is abundantly found in fruits and vegetables, with multiple roles including antitumor, hepatoprotective, and antidepressant [138]. Upon depression treatment, fisetin exerted a well-being response to the lipopolysaccharide-induced model by neuroprotective and anti-inflammation effects, except by inhibiting monoamine oxidase (MA0) $[139,140]$. It was able to reverse the expression of proinflammatory cytokines (IL-1 $1 \beta$, IL-6, and TNF- $\alpha$ ) and reduce iNOS mRNA expression by modulating the NF-kB pathway [140].

Resveratrol: Resveratrol is a natural phytoalexin, widely present in grapes, peanuts, and Veratrum nigrum (huzhang, 虎杖) [141]. Mounting evidence shows that resveratrol possesses various bioactivities, including cancer suppression, inflammation inhibition, oxidation-reduction, and many others. For depression, resveratrol has been reported to prevent depressive disorder depression in animals triggered by SD or CUMS $[142,143]$. The prevention was ascribed to a decrease of pro-inflammation cytokines (TNF- $\alpha$, IL$\mathrm{I} \beta, \mathrm{GM}-\mathrm{CSF}, \mathrm{NF}-\mathrm{kB}$ ) in peripheral and central positions, including the spleen, hippocampus, and locus coeruleus. El-Fattah AAA, et al. [143] found that resveratrol can reveal depression-like phenotypes of depression rats induced by CUMS, which was relevant to the suppression of MDA and increase of GSH in the hippocampus. Likewise, chronic treatment of resveratrol manifests an obvious antidepressant effect on Wistar-Kyoto (WKY) rats, a putative and non-induced animal model of depression [144]. Overall, resveratrol may be a potential therapeutic drug for depression.

Esculetin: Esculetin, a plant coumarin derived from the Fraxini cortex (qinpi, 秦皮), exhibited antidepressant-like effects on depressive mice induced by lipopolysaccharide $[145,146]$. It can significantly reduce pro-inflammation cytokines (IL-6, IL-1 $\beta$, and TNF- $\alpha$ ) in serum and hippocampus, attenuate the expressions of inflammation-related proteins (iNOS, COX-2, p-IKK $\alpha, p-I K K \beta$, $\mathrm{p}-\mathrm{I \kappa} \mathrm{B} \alpha$, and $\mathrm{p}-\mathrm{NF}-\mathrm{kB}$ p65) and upregulate protein expression of BDNF and $p-T r k B$ in the hippocampus [146].

Crocin: Crocin, derived from Croci stigma (xihonghua, 西 红花), has been reported to ameliorate depressive behavior in mice induced by lipopolysaccharide or CORT $[147,148]$. The amelioration was related to a reduction in the priming of NLRP3 inflammasome and pro-inflammation cytokines (IL-1 $\beta$, IL-6, IL18 , TNF- $\alpha$ ). As well, crocin also decreases the ratio of M1/M2 of microglia and the production of cytokines (NO, TNF- $\alpha$, IL-1 $1 \beta$, ROS,
iNOS, and NF-kB p65) in BV-2 microglial cells [147]. Overall, it may be useful for the treatment of depressive disorder by inhibiting the NLRP3 inflammasome and NF- $\mathrm{kB}$ pathway and suppressing microglial activation.

Proanthocyanidins: Proanthocyanidins are flavonoids, mostly found in grapes, apples, sorghum, cherry, and other plants [149]. The TCM of Hippophae fructus (shaji, 沙棘) is also one of the main sources of phytomedicine. Jiang X, et al. [150] found that proanthocyanidin reduced the immobility time of FST and TST on the lipopolysaccharide-induced depression mice. These data performed that proanthocyanidin inhibited the overexpression of iNOS, COX-2, and NF-kB in the hippocampus, PFC, and amygdala, suggested that proanthocyanidin has an effective therapeutic role on depression by modulating the NF-kB pathway [150].

\section{Discussion}

Depression is a well-known neurological disease with a wide incidence, and many various mechanisms have been proposed to explain the disease, such as dysfunction of the monoamine transmitter system, hyperactive activation of the HPA axis [151], neuroinflammation [152], and neuroplasticity [153]. Therefore, neurotransmitter balance, neuroendocrine homeostasis, neural plasticity, and neuroinflammation are the focal points of many researchers to explore the pathogenesis of depression. Take together; researchers believe that the prevention and treatment of depression involve various signaling pathways, including the nuclear factor kappa B (NF-kB) pathway, peroxisome proliferatoractivated receptor gamma (PPAR $)$ pathway, NLRP3/caspase-1/ IL-1 $\beta$ pathway, BDNF-ERK signaling pathway, ROCK/Akt pathway, and MEK pathway. However, existing researches are excessively scattered and lack systematicness, and it is necessary to study it systematically and intensively. Natural products come from natural creatures, which are inexhaustible treasures. At present, multiple natural products with neuropharmacological effects have been used to treat depressive disorder and depressive-like symptoms, such as phenols and flavonoids [154,155]. Hence, this article summarizes natural products with antidepressant effects. The results showed that Umbelliferae had the highest frequency of occurrence and may be the main source of antidepressant natural products, such as ferulic acid [33-36], umbelliferone [46-49], and apigenin [135137].

Tracing back to its plant origin, it is found that most of its original plants are Chinese medicine with an obvious antidepressant effect. These plants include chaihu, danggui, jixuecao, qincai, and so on. Closely followed by Rutaceae and Ranunculaceae, representative compounds include naringenin [38-43, 45] and paeonol [117, 118]. The composition of traditional Chinese medicine is complex. Some compounds played antidepressant roles by regulating unique mechanisms like restoration of astrocytic dysfunctions 
and suppression of microglial activation, while others modified oxidation and inflammatory reaction. It is the only way to find the best component with a significant curative effect in the complex and various components from prescription to medicine and then to compound or single component research. However, a series of profound studies, including animal studies and clinical trials, are needed to identify the latent side effects of these compounds to treat this complex disease and to further confirm the great potentiality of these compounds as candidate drugs for depressive disorder. In the aspect of animal model, stress exposure is the most common molding method, because it can simulate the clinical disease process of humans to the greatest extent, including chronic mild stress $[10,11]$, social defeat stress $[11,12]$. However, they have applied various animal models, including the stress model, chemical induction model, and surgical model.

The stimulation method in the stress model includes chronic unpredictable mild stress, chronic unpredictable stress, and chronic social defeat stress, or socially defeated, which can be used to establish the depression model. In the chemical induction model, there are repetitive injections of lipopolysaccharide, corticosterone, reserpine, and 3,4-methylenedioxymethamphetamine; and the surgical model is olfactory bulbectomized. Nevertheless, the validation research is not deep enough, just like the antidepressant effect of one compound on different animal models (Table 1). If these researchers can do that, the antidepressant status of the above natural products will be consolidated and strengthened.

Table 1: Summary of the main botanical sources and pharmacological effects of natural compounds from TCMs for depressive diseases.

\begin{tabular}{|c|c|c|c|c|c|c|}
\hline No. & $\begin{array}{l}\text { Compound } \\
\text { Names }\end{array}$ & Family & Main Botanical Source & Structures & Mechanisms & Ref. \\
\hline 1 & Ferulic acid & Umbelliferae & $\begin{array}{c}\text { Ferulae Resina (e'wei, 阿 } \\
\text { 魏), Angelicae Sinensis Radix } \\
\text { (danggui, 当归), Aconiti } \\
\text { Radix (chuanxiong, 川芎), } \\
\text { Cimicifugae Rhizoma (sheng- } \\
\text { ma, 升麻), and Ziziphi Spi- } \\
\text { nosae Semen (suanzaoren, } \\
\text { 酸梖仁) }\end{array}$ & Ferulic acid, CAS: $1135-24-6$ & $\begin{array}{l}\text { inhibit MAO or the } \\
\text { receptors of 5-HT1A/5- } \\
\text { HT2A }\end{array}$ & [33-36] \\
\hline 2 & Naringenin & Rutaceae & $\begin{array}{l}\text { Menthea haplocalycis herba } \\
\text { (bohe, 薄荷) and Auranrii } \\
\text { fractus (zhiqiao, 枳壳) }\end{array}$ & Naringenin, CAS: 480-41-1 & $\begin{array}{c}\text { increase the 5-HT level } \\
\text { by inhibiting MAO or } \\
\text { regulating the metabolic } \\
\text { process of tryptophan }\end{array}$ & {$[37,39-45]$} \\
\hline 3 & Umbelliferone & Umbelliferae & $\begin{array}{l}\text { Angelicae pubescentis radix } \\
\text { (duhuo, 独活) }\end{array}$ & Umbelliferone, CAS: $93-35-6$ & \begin{tabular}{|} 
inhibit the activity of \\
MAO \\
modulate the ROCK/ \\
Akt pathway or GSK-3 $\beta /$ \\
PI3K/Akt pathway to in- \\
hibit neuronal apoptosis
\end{tabular} & [46-49] \\
\hline 4 & Chrysin & Bignoniaceae & $\begin{array}{l}\text { Oroxyli semen (muhudie, 木 } \\
\text { 蝴蝶) }\end{array}$ & Chrysin, CAS: 480-40-0 & $\begin{array}{c}\text { regulate the level of } \\
\text { 5-HT and its production } \\
\text { and metabolism } \\
\text { increase BDNF level }\end{array}$ & [50-58] \\
\hline 5 & Curcumin & $\begin{array}{c}\text { Zingiberaceae } \text { and } \\
\text { Araceae }\end{array}$ & $\begin{array}{c}\text { Wenyujin Rhizoma Concisum } \\
\text { (jianghuang, 姜黄), Curcu- } \\
\text { mae Radix (yujin, 郁金), and } \\
\text { Curcumae Rhizzoma (e'zhu, } \\
\text { 莪术). }\end{array}$ & Curcumin, CAS: 458-37-7 & $\begin{array}{c}\text { regulate the balance } \\
\text { between glutamate and } \\
\text { GABA via GABAA recep- } \\
\text { tor and GluN2B }\end{array}$ & [64-67] \\
\hline
\end{tabular}




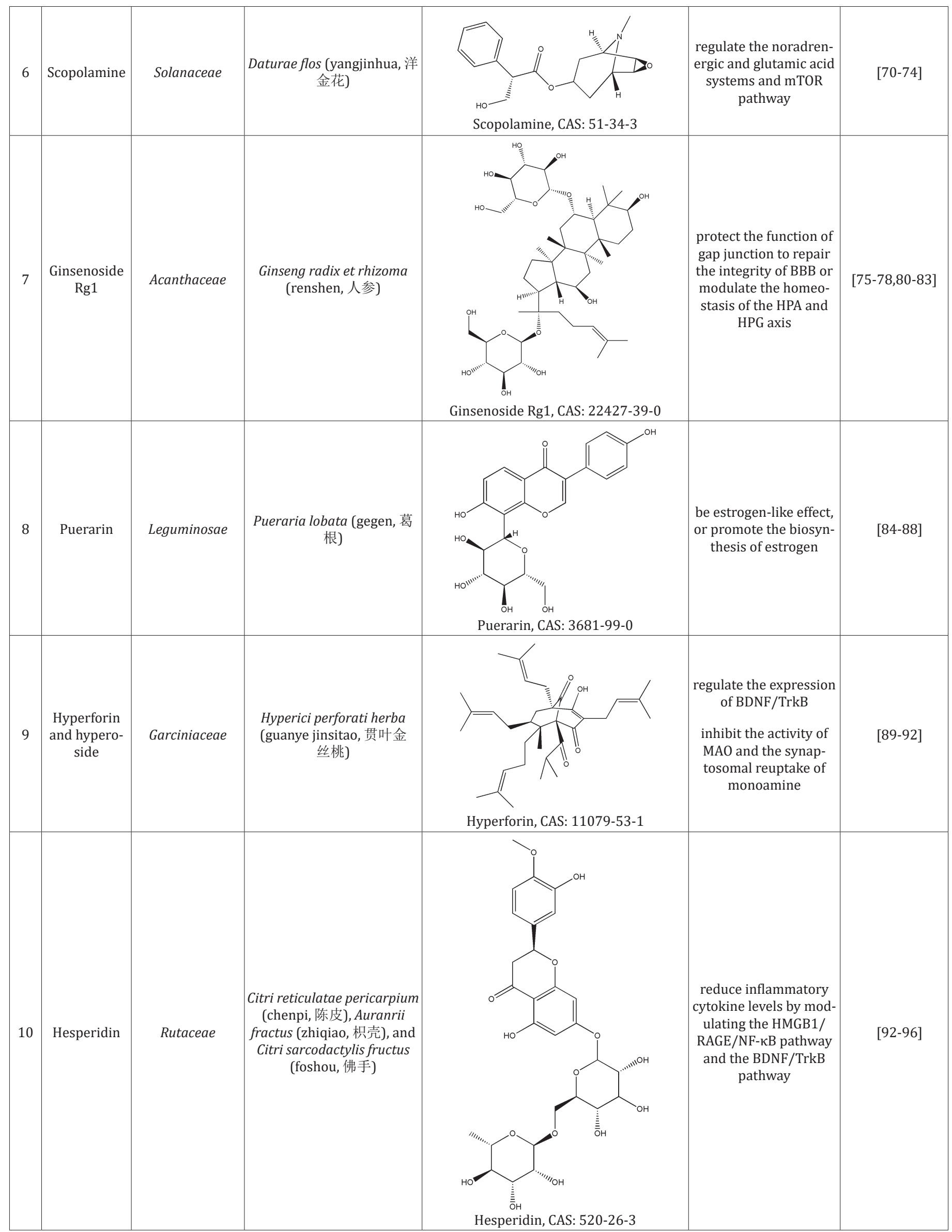




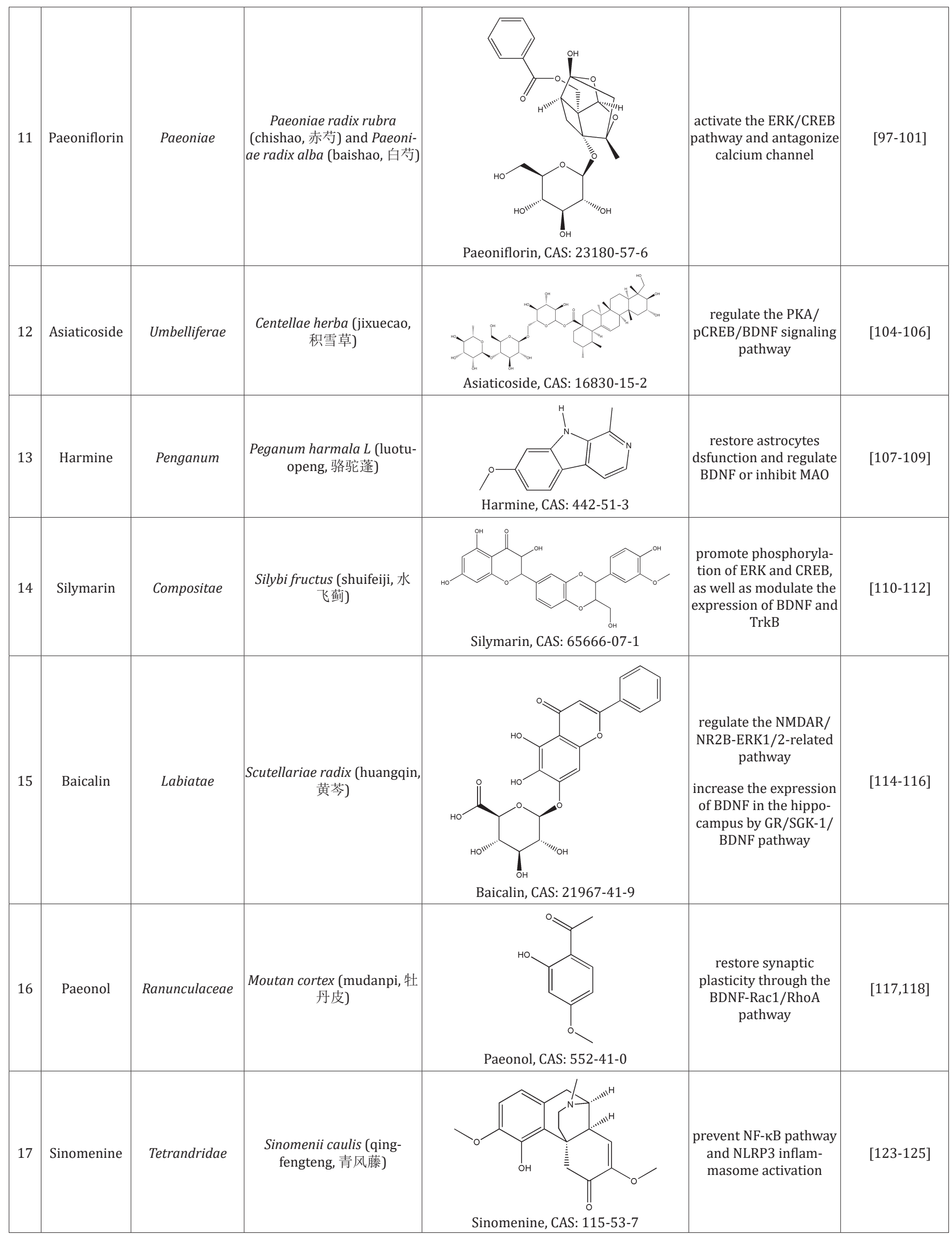




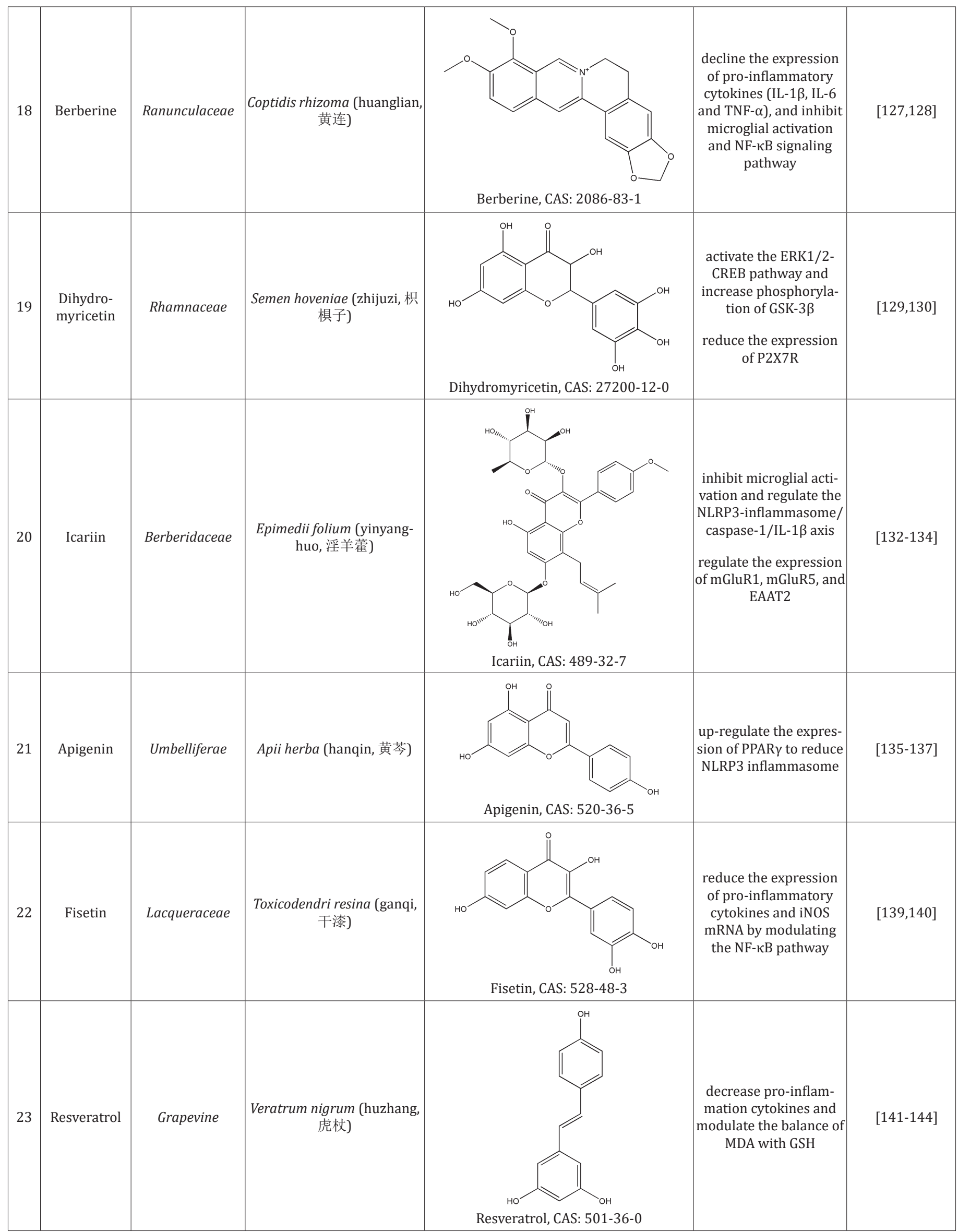




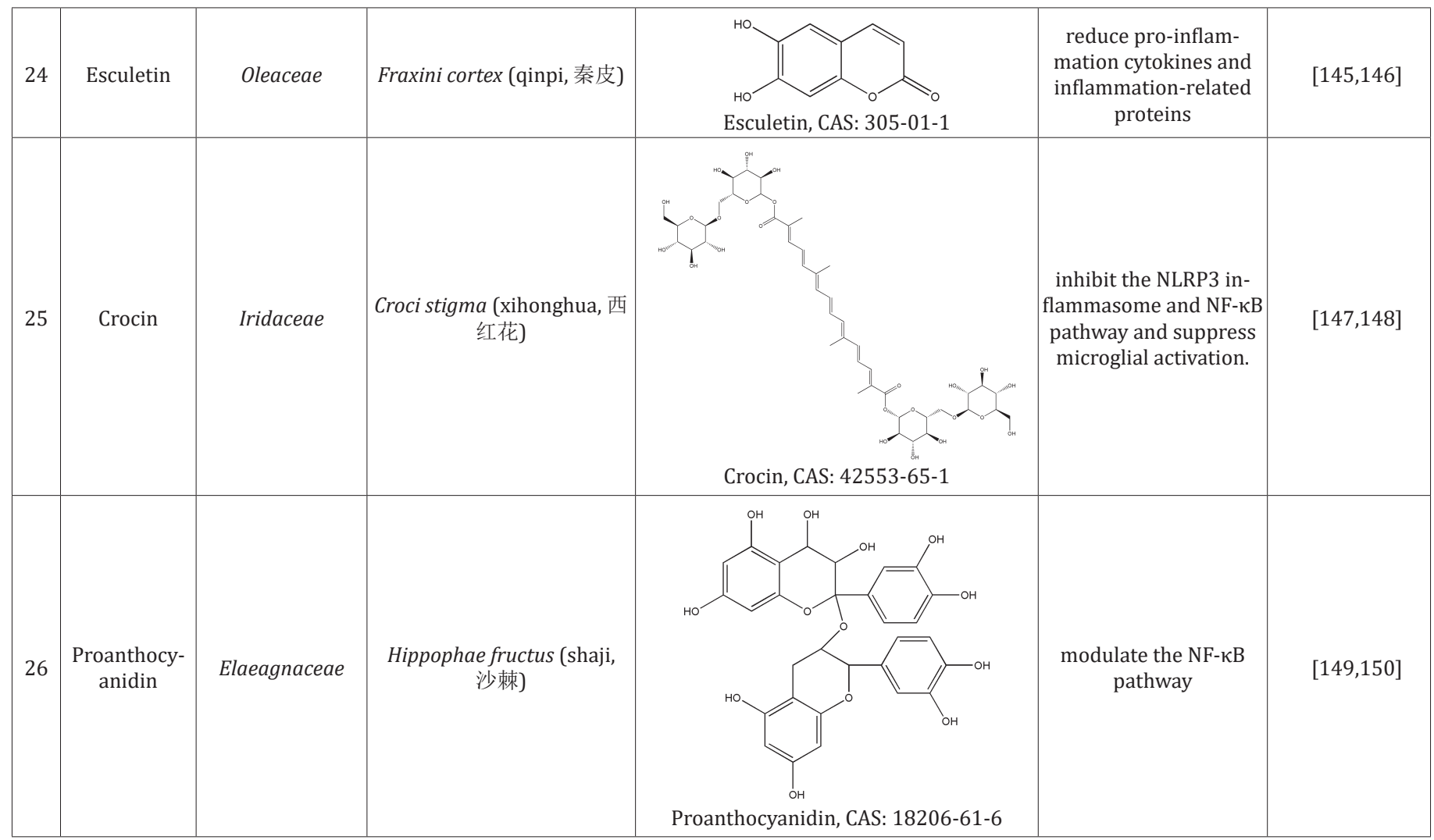

\section{Conclusion}

This paper reviewed the antidepressant activity and effect of various natural products. We classified natural products according to the botanical source and summarized their mechanism of action. Natural products are promising in that they have the great potentiality to treat depressive disorder. However, further animal studies and clinical trials are required to confirm the potential of these compounds as therapeutics for depressive disorder.

\section{Acknowledgement}

This research was funded by National Science and Technology Major Projects of China for "Major New Drugs Innovation and Development"[No. 2017ZX09309026], and National Natural Science Foundation of China [No. 81874464].

\section{Conflicts of Interest}

The authors declare no conflict of interest.

\section{References}

1. Kessler RC (2012) The costs of depression. Psychiatr Clin North Am 35(1): 1-14.

2. Mokdad AH, Ballestros K, Echko M, Alex Lee, Abdur Rahman Khan, et al. (2018) The State of US Health, 1990-2016: Burden of Diseases, Injuries, and Risk Factors Among US States. JAMA 319(14): 1444-1472.

3. Birmaher B, Arbelaez C, Brent D (2002) Course and outcome of child and adolescent major depressive disorder. Child Adolesc Psychiatr Clin N Am 11(3): 619-637.
4. Bloom D, Cafiero E, Jané-Llopis E, Abrahams-Gessel S, Weiss J, et al. (2011) The Global Economic Burden of No communicable Diseases.

5. (2014) Organization WH. Preventing suicide: A global imperative. World Health Organization.

6. Ensink JBM, Moor MHD, Zafarmand MH, Laat SD, Uitterlinden A, et al. (2020) Maternal environmental risk factors and the development of internalizing and externalizing problems in childhood: The complex role of genetic factors. American Journal of Medical Genetics Part B Neuropsychiatric Genetics 183(1): 17-25.

7. Smart C, Strathdee G, Watson S, Murgatroyd C, McAllister Williams $\mathrm{RH}$, et al. (2015) Early life trauma, depression and the glucocorticoid receptor gene--an epigenetic perspective. Psychol Med 45(16): 33933410.

8. Kaut O, Schmitt I, Hofmann A, Hoffmann P, Schlaepfer TE, et al. (2015) Aberrant NMDA receptor DNA methylation detected by epigenomewide analysis of hippocampus and prefrontal cortex in major depression. Eur Arch Psychiatry Clin Neurosci 265(4): 331-341.

9. Planchez B, Surget A, Belzung C (2019) Animal models of major depression: Drawbacks and challenges. Journal of neural transmission (Vienna, Austria: 1996) 126(11): 1383-1408.

10. Willner P (2017) The chronic mild stress (CMS) model of depression: History, evaluation and usage. Neurobiol Stress 6: 78-93.

11. Iñiguez SD, Riggs LM, Nieto SJ, Dayrit G, Zamora NN, et al. (2014) Social defeat stress induces a depression-like phenotype in adolescent male c57BL/6 mice. Stress (Amsterdam, Netherlands) 17(3): 247-255.

12. Newman EL, Covington HE, Suh J, Bicakci MB, Ressler KJ, et al. (2019) Fighting Females: Neural and Behavioral Consequences of Social Defeat Stress in Female Mice. Biol Psychiatry 86(9): 657-668.

13. Sekio M, Seki K (2014) Lipopolysaccharide-induced depressive-like behavior is associated with $\alpha_{1}$-adrenoceptor dependent downregulation 
of the membrane GluR1 subunit in the mouse medial prefrontal cortex and ventral tegmental area. Int J Neuropsychopharmacol 18(1).

14. Sturm M, Becker A, Schroeder A, Bilkei Gorzo A, Zimmer A, et al. (2015) Effect of chronic corticosterone application on depression-like behavior in C57BL/6N and C57BL/6J mice. Genes Brain Behav 14(3): 292-300.

15. Mekiri M, Gardier AM, David DJ, Guilloux JP (2017) Chronic corticosterone administration effects on behavioral emotionality in female c57bl6 mice. Exp Clin Psychopharmacol 25(4): 94-104.

16. Freis ED (1954) Mental depression in hypertensive patients treated for long periods with large doses of reserpine. N Engl J Med 251(25): 1006-1008.

17. Nagakura Y, Oe T, Aoki T, Matsuoka N (2009) Biogenic amine depletion causes chronic muscular pain and tactile allodynia accompanied by depression: A putative animal model of fibromyalgia. Pain 146(1-2): 26-33.

18. Berge L, Andreassen BK, Stenehjem JS, et al. (2019) Cardiovascular, antidepressant and immunosuppressive drug use in relation to risk of cutaneous melanoma: A protocol for a prospective case-control study. BMJ Open 9(2).

19. Yu H, Li M, Shen X, Dan Lv, Xin Sun, et al. (2018) The Requirement of L-Type Voltage-Dependent Calcium Channel (L-VDCC) in the RapidActing Antidepressant-Like Effects of Scopolamine in Mice. Int J Neuropsychopharmacol 21(2): 175-186.

20. Nabavi SF, Dean OM, Turner A, Sureda A, Daglia M, et al. (2015) Oxidative stress and post-stroke depression: possible therapeutic role of polyphenols. Curr Med Chem 22(3): 343-51.

21. Zhang LM, Wang XY, Zhao N, Yu-Lu Wang, Xiao-Xu Hu, et al. (2017) Neurochemical and behavioural effects of hypidone hydrochloride (YL0919): a novel combined selective 5-HT reuptake inhibitor and partial 5-HT agonist. Br J Pharmacol 174(9): 769-780.

22. Herbet M, Gawrońska Grzywacz M, Izdebska M, Piątkowska Chmiel I, Jagiełło-Wójtowicz E, et al. (2016) Impact of combined treatment with rosuvastatin and antidepressants on liver and kidney function in rats. Exp Ther Med 11(4): 1459-1464.

23. Khan A, Faucett J, Lichtenberg P, Kirsch I, Brown WA, et al. (2012) A systematic review of comparative efficacy of treatments and controls for depression. PLoS One 7(7).

24. Gujral S, Aizenstein H, Reynolds CF, Butters MA, Erickson KI, et al (2017) Exercise effects on depression: Possible neural mechanisms. Gen Hosp Psychiatry 49: 2-10.

25. Allen J, Schnyer R, As Hitt S, Moreno F, Manber R, et al. (2006) Acupuncture for depression: A randomized controlled trial. J Clin psychiatry 67(11): 1665-1673.

26. Nabavi SF, Nabavi SM, Mirzaei M, Moghaddam AH, et al. (2012) Protective effect of quercetin against sodium fluoride induced oxidative stress in rat's heart. Food Funct 3(4): 437-441.

27. Nabavi SF, Nabavi SM, Ebrahimzadeh MA, Jafari N, Yazdanpanah S, et al. (2013) Biological Activities of Freshwater Algae,Spirogyra singularis Nordstedt. Journal of Aquatic Food Product Technology 22(1): 58-65.

28. Kerage D, Sloan EK, Mattarollo S, McCombe PA (2019) Interaction of neurotransmitters and neurochemicals with lymphocytes J Neuroimmunol 332: 99-111.

29. Naoi M, Maruyama W, Shamoto Nagai M (2018) Type A monoamine oxidase and serotonin are coordinately involved in depressive disorders: From neurotransmitter imbalance to impaired neurogenesis. Journal of neural transmission (Vienna, Austria: 1996) 125(1): 53-66.

30. Blier P, El Mansari M (2013) Serotonin and beyond: therapeutics for major depression. Philos Trans R Soc Lond B Biol Sci 368(1615): 20120536
31. Liu Y, Zhao J, Guo W (2018) Emotional Roles of Mono-Aminergic Neurotransmitters in Major Depressive Disorder and Anxiety Disorders. Front Psychol 9: 2201.

32. Pathak L, Agrawal Y, Dhir A (2013) Natural polyphenols in the management of major depression. Expert Opin Investig Drugs 22(7): 863-880

33. Zhang YJ, Huang X, Wang Y, Xie Y, Qiu XJ, et al. (2011) Ferulic acidinduced anti-depression and prokinetics similar to Chaihu-Shugan-San via polypharmacology. Brain Res Bull 86(3-4): 222-228.

34. Chen J, Lin D, Zhang C, Li G, Zhang N, et al. (2015) Antidepressant-like effects of ferulic acid: involvement of serotonergic and norepinergic systems. Metab Brain Dis 30(1): 129-136.

35. Zeni AL, Zomkowski AD, Maraschin M, Rodrigues AL, Tasca CI, et al. (2012) Ferulic acid exerts antidepressant-like effect in the tail suspension test in mice: evidence for the involvement of the serotonergic system. Eur J Pharmacol 679(1-3): 68-74.

36. Li G, Ruan L, Chen R, Renye Wang, Xupei Xie, et al. (2015) Synergistic antidepressant-like effect of ferulic acid in combination with piperine: involvement of monoaminergic system. Metab Brain Dis 30(6): 150514.

37. Saenz J, Santa María C, Reyes Quiroz ME, Isabel Geniz, Juan Jiménez, et al. (2018) Grapefruit Flavonoid Naringenin Regulates the Expression of LXR $\alpha$ in THP-1 Macrophages by Modulating AMP-Activated Protein Kinase. Mol Pharm 15(5): 1735-1745.

38. Zeng WF, Zhang FY, Du GJ, Jin LT, Liang W, et al. (2018) Research updates on a novel immunomodulator, Naringenin. Progress in Biochemistry \& Biophysics 45: 915-925.

39. Bansal Y, Singh R, Saroj P, Sodhi RK, Kuhad A, et al. (2018) Naringenin protects against oxido-inflammatory aberrations and altered tryptophan metabolism in olfactory bulbectomized-mice model of depression. Toxicol Appl Pharmacol 355: 257-268.

40. Umukoro S, Kalejaye HA, Ben Azu B, Ajayi AM (2018) Naringenin attenuates behavioral derangements induced by social defeat stress in mice via inhibition of acetylcholinesterase activity, oxidative stress and release of pro-inflammatory cytokines. Biomedicine \& pharmacotherapy $=$ Biomedecine $\&$ pharmacotherapie 105: 714-723.

41. Yi LT, Li CF, Zhan X, Cui CC, Xiao F, et al. (2010) Involvement of monoaminergic system in the antidepressant-like effect of the flavonoid naringenin in mice. Prog Neuropsychopharmacol Biol Psychiatry 34(7): 1223-1228.

42. Tayyab M, Farheen S, Khanam N, Mobarak Hossain M, Shahi MH, et al. (2019) Antidepressant and Neuroprotective Effects of Naringenin via Sonic Hedgehog-GLI1 Cell Signaling Pathway in a Rat Model of Chronic Unpredictable Mild Stress. Neuromolecular Med 21(3): 250-261.

43. Ben Azu B, Nwoke EE, Umukoro S, Aderibigbe A0, Ajayi AM, et al. (2018) Evaluation of the Neurobehavioral Properties of Naringin in Swiss Mice. Drug Res (Stuttg) 68(8): 465-474.

44. Zhang X, Han L, Liu J, Xu Q, Guo Y, et al. (2018) Pharmacokinetic Study of 7 Compounds Following Oral Administration of Fructus Aurantii to Depressive Rats. Front Pharmacol 9: 131.

45. Olsen HT, Stafford GI, Van Staden J, Christensen SB, Jäger AK, et al. (2008) Isolation of the MAO-inhibitor naringenin from Mentha aquatica L. J Ethnopharmacol 117(3): 500-502.

46. Lee B, Yeom M, Shim I, Lee H, Hahm DH, et al. (2020) Umbelliferone modulates depression-like symptoms by altering monoamines in a rat post-traumatic stress disorder model. J Nat Med 74: 377-386.

47. Dhiman P, Malik N, Khatkar A (2018) Exploration of Umbelliferone Based Derivatives as Potent MAO Inhibitors: Dry vs. Wet Lab Evaluation. Curr Top Med Chem 18(21): 1857-1871. 
48. Qin T, Fang F, Song M, Li R, Ma Z, et al. (2017) Umbelliferone reverses depression-like behavior in chronic unpredictable mild stress-induced rats by attenuating neuronal apoptosis via regulating ROCK/Akt pathway. Behav Brain Res 317: 147-156.

49. Su Q, Tao W, Wang H, Chen Y, Huang H, et al. (2016) Umbelliferone attenuates unpredictable chronic mild stress induced-insulin resistance in rats. IUBMB Life 68(5): 403-409.

50. Nabavi SF, Braidy N, Habtemariam S, Orhan IE, Daglia M, et al. (2015) Neuroprotective effects of chrysin: From chemistry to medicine. Neurochem Int 90: 224-231.

51. Filho CB, Jesse CR, Donato F, R Giacomeli, L Del Fabbro, et al. (2015) Chronic unpredictable mild stress decreases BDNF and NGF levels and $\mathrm{Na}(+), \mathrm{K}(+)$-ATPase activity in the hippocampus and prefrontal cortex of mice: antidepressant effect of chrysin. Neuroscience 289: 367-80.

52. Rashno M, Ghaderi S, Nesari A, Khorsandi L, Farbood Y, et al. (2020) Chrysin attenuates traumatic brain injury-induced recognition memory decline, and anxiety/depression-like behaviors in rats: Insights into underlying mechanisms. Psychopharmacology (Berl) 237(6): 16071619.

53. Farkhondeh T, Jalali S, Ashrafizadeh M, Samarghandian S, Samini F, et al. (2020) Effects of Chrysin on Serum Corticosterone Levels and Brain Oxidative Damages Induced by Immobilization in Rat. Cardiovasc Hematol Disord Drug Targets 20(1): 47-53.

54. Filho CB, Jesse CR, Donato F, Del Fabbro L, De Gomes MG, et al. (2016) Neurochemical factors associated with the antidepressant-like effect of flavonoid chrysin in chronically stressed mice. Eur J Pharmacol 791 284-296.

55. Wu J, Wang Y, Cui W, Zhou W, Zhao X, et al. (2020) 5-HT receptormediated attenuation of heat hyperalgesia and mechanical allodynia by chrysin in mice with experimental mononeuropathy. Reg Anesth Pain Med 45(8): 610-619.

56. Cueto Escobedo J, AndradeSoto J, Lima Maximino M, Maximino C, Hernández López F, et al. (2020) Involvement of GABAergic system in the antidepressant-like effects of chrysin (5,7-dihydroxyflavone) in ovariectomized rats in the forced swim test: comparison with neurosteroids. Behav Brain Res 386: 112590

57. Filho CB, Jesse CR, Donato F, Del Fabbro L, Gomes de Gomes M, et al. Chrysin promotes attenuation of depressive-like behavior and hippocampal dysfunction resulting from olfactory bulbectomy in mice. Chem Biol Interact 260: 154-162.

58. Bortolotto VC, Pinheiro FC, Araujo SM, Poetini MR, Bertolazi BS, et al. (2018) Chrysin reverses the depressive-like behavior induced by hypothyroidism in female mice by regulating hippocampal serotonin and dopamine. Eur J Pharmacol 822: 78-84.

59. Lener MS, Niciu MJ, Ballard ED, Park M, Park LT, et al. (2017) Glutamate and Gamma-Aminobutyric Acid Systems in the Pathophysiology of Major Depression and Antidepressant Response to Ketamine. Biol Psychiatry 81(10): 886-897.

60. Liao JW, Wang SS, Yang HH, Ma P, Li CR, et al. (2020) Comparative analysis of serum glutamate and gamma-aminobutyric acid levels in patients with bipolar depressive disorder and major depression disorder. Zhonghua Yi Xue Za Zhi 100(23): 1800-1804.

61. Marsden WN (2011) Stressor-induced NMDAR dysfunction as a unifying hypothesis for the aetiology, pathogenesis and comorbidity of clinical depression. Med Hypotheses 77(4): 508-528.

62. Li Y, Dharkar P, Han TH, Serpe M, Lee CH, et al. (2016) Novel Functional Properties of Drosophila CNS Glutamate Receptors. Neuron 92(5): 1036-1048.
63. Mann JJ, Oquendo MA, Watson KT, Boldrini M, Malone KM, et al. (2014) Anxiety in major depression and cerebrospinal fluid free gammaaminobutyric acid. Depress Anxiety 31(10): 814-821.

64. Zhang L, Xu T, Wang S, Yu L, Liu D, et al. (2013) NMDA GluN2B receptors involved in the antidepressant effects of curcumin in the forced swim test. Prog Neuropsychopharmacol Biol Psychiatry 40: 12-17.

65. Zhao X, Wang C, Zhang JF, Liu L, Liu AM, et al. (2014) Chronic curcumin treatment normalizes depression-like behaviors in mice with mononeuropathy: Involvement of supraspinal serotonergic system and GABAA receptor. Psychopharmacology (Berl) 231(10): 2171-2187.

66. Wang Z, Zhang Q, Yuan L, Wang S, Liu L, et al. (2014) The effects of curcumin on depressive-like behavior in mice after lipopolysaccharide administration. Behav Brain Res 274: 282-290.

67. Lin TY, Lu CW, Wang CC, Wang YC, Wang SJ, et al. (2011) Curcumin inhibits glutamate release in nerve terminals from rat prefrontal cortex: possible relevance to its antidepressant mechanism. Prog Neuropsychopharmacol Biol Psychiatry 35(7): 1785-1793.

68. Fernandes SS, Koth AP, Parfitt GM, Cordeiro MF, Peixoto CS, et al. (2018) Enhanced cholinergic-tone during the stress induce a depressive-like state in mice. Behav Brain Res 347: 17-25.

69. Cheng J, Umschweif G, Leung J, Sagi Y, Greengard P, et al. (2019) HCN2 Channels in Cholinergic Interneurons of Nucleus Accumbens Shell Regulate Depressive Behaviors Neuron 101(4): 662-672.

70. Wohleb ES, Wu M, Gerhard DM, Marina R Picciotto, Meenakshi Alreja, et al. (2016) GABA interneurons mediate the rapid antidepressant-like effects of scopolamine. J Clin Invest 126(7): 2482-2494.

71. Martin AE, Schober DA, Nikolayev A, Tolstikov VV, Witkin JM, et al. (2017) Further Evaluation of Mechanisms Associated with the Antidepressantlike Signature of Scopolamine in Mice. CNS Neurol Disord Drug Targets 16(4): 492-500.

72. Palucha Poniewiera A, Podkowa K, Lenda T, Pilc A. The involvement of monoaminergic neurotransmission in the antidepressant-like action of scopolamine in the tail suspension test. Progress in NeuroPsychopharmacology and Biological Psychiatry 79: 155-161.

73. Podkowa K, Podkowa A, Sałat K, Lenda T, Pałucha Poniewiera A, et al. (2016) Antidepressant-like effects of scopolamine in mice are enhanced by the group II mGlu receptor antagonist LY341495. Neuropharmacology 111: 169-179.

74. Yu H, Li M, Zhou D, Lv D, Wang C, et al. (2017) Vesicular glutamate transporter 1 (VGLUT1)-mediated glutamate release and membrane GluA1 activation is involved in the rapid antidepressant-like effects of scopolamine in mice. Neuropharmacology 131: 209-222.

75. Jiang N, Lv J, Wang H, Huang H, Wang Q, et al. (2020) Ginsenoside Rg1 ameliorates chronic social defeat stress-induced depressive-like behaviors and hippocampal neuroinflammation. Life sciences 252: 117669.

76. Fan C, Song Q, Wang P, Li Y, Yang M, et al. (2018) Neuroprotective Effects of Ginsenoside-Rg1 Against Depression-Like Behaviors via Suppressing Glial Activation, Synaptic Deficits, and Neuronal Apoptosis in Rats. Front Immunol 9: 2889.

77. Li Y, Wang L, Wang P, Fan C, Zhang P, et al. (2020) Ginsenoside-Rg1 Rescues Stress-Induced Depression-Like Behaviors via Suppression of Oxidative Stress and Neural Inflammation in Rats. Oxid Med Cell Longev 2020: 2325391.

78. Yu H, Fan C, Yang L, Yu S, Song Q, et al. (2018) Ginsenoside Rg1 Prevents Chronic Stress-Induced Depression-Like Behaviors and Neuronal Structural Plasticity in Rats. Cell Physiol Biochem 48(6): 2470-2482. 
79. Ning J, Jing Wei L, Hai Xia W, Huang Hong, Wang Qiong, et al. (2019) Antidepressant-like Effects of Ginsenoside Rg1 in the Chronic Restraint Stress-induced Rat Model. Digital Chinese Medicine 2(4): 207-218.

80. Lou YX, Wang ZZ, Xia CY, Mou Z, Ren Q et al. (2020) The protective effect of ginsenoside $\operatorname{Rg} 1$ on depression may benefit from the gap junction function in hippocampal astrocytes. Eur J Pharmacol 882: 173309.

81. Xia CY, Wang ZZ, Wang HQ, Ren SY, Lou YX, et al. (2020) Connexin 43 A novel ginsenoside Rg1-sensitive target in a rat model of depression. Neuropharmacology 17: 108041.

82. Xia CY, Chu SF, Zhang S, Gao Y, Ren Q et al. (2017) Ginsenoside Rg1 alleviates corticosterone-induced dysfunction of gap junctions in astrocytes. J Ethnopharmacol 208: 207-213.

83. Mou Z, Huang Q Chu S F, Zhang M J, Hu J F, et al. (2017) Antidepressive effects of ginsenoside $\operatorname{Rg} 1$ via regulation of HPA and HPG axis. Biomedicine \& pharmacotherapy = Biomedecine $\&$ pharmacotherapie 92: $962-971$.

84. Zhang S, Chen L, Zhou Z, Fan W, Liu S, et al. (2019) Effects of Puerarin on Clinical Parameters, Vascular Endothelial Function, and Inflammatory Factors in Patients with Coronary Artery Disease. Med Sci Monit 25: 402-408.

85. Huang CC, Tsai MH, Wu YC, Chen KT, Chuang HW, et al (2018) Activity Dependent Mammalian Target of Rapamycin Pathway and Brain Derived Neurotrophic Factor Release Is Required for the Rapid Antidepressant Effects of Puerarin. Am J Chin Med, p. 1-16.

86. Cheng J, Chen M, Zhu JX, Li CF, Zhang QP, et al (2019) FGF-2 signaling activation in the hippocampus contributes to the behavioral and cellular responses to puerarin. Biochem Pharmacol 168: 91-99.

87. Tantipongpiradet A, Monthakantira O, Vipatpakpaiboon O, Khampukdee C, Umehara K, et al. (2019) Effects of Puerarin on the OvariectomyInduced Depressive-Like Behavior in ICR Mice and Its Possible Mechanism of Action. Molecules (Basel, Switzerland) 24(24).

88. Qiu ZK, Zhong DS, He JL, Liu X, Chen JS, et al. (2018) The anxiolytic-like effects of puerarin are associated with the changes of monoaminergic neurotransmitters and biosynthesis of allopregnanolone in the brain. Metab Brain Dis 33(1): 167-175.

89. Galeotti N (2017) Hypericum perforatum (St John's wort) beyond depression: A therapeutic perspective for pain conditions. J Ethnopharmacol 200: 136-146.

90. Szewczyk B, Pochwat B, Muszyńska B, Opoka W, Krakowska A, et al. (2019) Antidepressant-like activity of hyperforin and changes in BDNF and zinc levels in mice exposed to chronic unpredictable mild stress. Behav Brain Res 372: 112045.

91. Leuner K, Li W, Amaral MD, Rudolph S, Calfa G, et al. (2013) Hyperforin modulates dendritic spine morphology in hippocampal pyramidal neurons by activating $\mathrm{Ca}(2+)$-permeable TRPC6 channels. Hippocampus 23(1): 40-52.

92. Gong Y, Yang Y, Chen X, Yang M, Huang D, etal. (2017) Hyperoside protects against chronic mild stress-induced learning and memory deficits. Biomedicine \& pharmacotherapy = Biomedecine \& pharmacotherapie 91: 831-840.

93. Cai L, Li R, Wu QQ, Wu TN (2013) Effect of hesperidin on behavior and HPA axis of rat model of chronic stress-induced depression. Zhongguo Zhong Yao Za Zhi 38(2): 229-233.

94. Sato M, Okuno A, Suzuki K, Ohsawa N, Inoue E, (2019) Dietary intake of the citrus flavonoid hesperidin affects stress-resilience and brain kynurenine levels in a subchronic and mild social defeat stress model in mice. Biosci Biotechnol Biochem 83(9): 1756-1765.

95. Li M, Shao H, Zhang X, Qin B, (2016) Hesperidin Alleviates Lipopolysaccharide-Induced Neuroinflammation in Mice by Promoting the miRNA-132 Pathway. Inflammation 39(5): 1681-1689.
96. Fu H, Liu L, Tong Y, Li Y, Zhang X, et al. (2019) The antidepressant effects of hesperidin on chronic unpredictable mild stress-induced mice. Eur J Pharmacol 853: 236-246.

97. Zhong X, Li G, Qiu F, Huang Z (2018) Paeoniflorin Ameliorates Chronic Stress-Induced Depression-Like Behaviors and Neuronal Damages in Rats via Activation of the ERK-CREB Pathway. Front Psychiatry 9: 772.

98. Chen L B, Qiu FM, Zhong XM, Hong C, Huang Z, et al. (2019) Promoting neurogenesis in hippocampal dentate gyrus of chronic unpredictable stress-induced depressive-like rats with paeoniflorin. J Integr Neurosci 18(1): 43-49.

99. Liu SC, Hu WY, Zhang W Y, Yang L, Li Y, et al. (2019) Paeoniflorin attenuates impairment of spatial learning and hippocampal long-term potentiation in mice subjected to chronic unpredictable mild stress. Psychopharmacology (Berl) 236(9): 2823-2834.

100.Mao QQ, Zhong XM, Feng CR, Pan AJ, Li ZY, et al. (2010) Protective effects of paeoniflorin against glutamate-induced neurotoxicity in PC12 cells via antioxidant mechanisms and $\mathrm{Ca}(2+)$ antagonism. Cell Mol Neurobiol 30(7): 1059-1066.

101.Mao QQ Zhong XM, Li ZY, Huang Z (2011) Paeoniflorin protects against NMDA-induced neurotoxicity in PC12 cells via Ca2+ antagonism. Phytother Res 25(5): 681-685.

102.Kavalali ET, Monteggia LM (2020) Targeting Homeostatic Synaptic Plasticity for Treatment of Mood Disorders. Neuron 106(5): 715-726.

103.Price JB, Bronars C, Erhardt S, Cullen KR, Schwieler L, et al. (2018) Bioenergetics and synaptic plasticity as potential targets for individualizing treatment for depression. Neurosci Biobehav Rev 90: 212-220.

104.Razali N, Ng CT, Fong LY (2019) Cardiovascular Protective Effects of Centella asiatica and Its Triterpenes: A Review. Planta Med 85(16): 1203-1215.

105.Luo L, Liu XL, Mu RH, Yong JW, Bin, et al. (2015) Hippocampal BDNF signaling restored with chronic asiaticoside treatment in depressionlike mice. Brain Res Bull 114: 62-9.

106.Wang L, Guo T, Guo Y, Xu Y (2020) Asiaticoside produces an antidepressant-like effect in a chronic unpredictable mild stress model of depression in mice, involving reversion of inflammation and the PKA/pCREB/BDNF signaling pathway. Mol Med Rep 22(3): 2364-2372.

107.Fortunato JJ, Reus GZ, Kirsch TR, Stringari RB, Fries GR, et al. (2010) J Chronic administration of harmine elicits antidepressant-like effects and increases BDNF levels in rat hippocampus. Journal of neural transmission (Vienna, Austria: 1996) 117(10): 1131-1137.

108.Liu F, Wu J, Gong Y, Peng W, Lei Z et al. (2017) Harmine produces antidepressant-like effects via restoration of astrocytic functions. Prog Neuropsychopharmacol Biol Psychiatry 79(Pt B): 258-267.

109.Giacobb BL, Doorduin J, Moraga Amaro R, Nazario LR, Schildt A, et al. (2020) Chronic harmine treatment has a delayed effect on mobility in control and socially defeated rats. Psychopharmacology (Berl) 237(6): 1595-1606.

110.Thakare VN, Aswar MK, Kulkarni YP, Patil RR, Patel BM, et al. (2017) Silymarin ameliorates experimentally induced depressive like behavior in rats: Involvement of hippocampal BDNF signaling, inflammatory cytokines and oxidative stress response. Physiol Behav 179: 401-410.

111.Thakare VN, Patil RR, Oswal RJ, Dhakane VD, Aswar MK, et al. (2018) Therapeutic potential of silymarin in chronic unpredictable mild stress induced depressive-like behavior in mice. Journal of psychopharmacology (Oxford, England) 32(2): 223-235.

112.Li YJ, Li YJ, Yang LD, Kun Z, Kai YZ, et al. (2018) Silibinin exerts antidepressant effects by improving neurogenesis through BDNF/TrkB pathway. Behav Brain Res 348: 184-191. 
113.Sowndhararajan K, Deepa P, Kim M, Park SJ, Kim S, et al. (2018) Neuroprotective and Cognitive Enhancement Potentials of Baicalin: A Review. Brain Sci 8(6): 104

114.Zhong J, Li G, Xu H, Wang Y, Shi M, et al. (2019) Baicalin ameliorates chronic mild stress-induced depression-like behaviors in mice and attenuates inflammatory cytokines and oxidative stress. Brazilian journal of medical and biological research = Revista brasileira de pesquisas medicas e biologicas 52(7): e8434.

115.Li YC, Wang LL, Pei YY, Shen JD, Li HB, et al. (2015) Baicalin decreases SGK1 expression in the hippocampus and reverses depressive-like behaviors induced by corticosterone. Neuroscience 311: 130-137.

116.Yu HY, Yin ZJ, Yang SJ, Ma SP, Qu R, et al. (2016) Baicalin Reverses Depressive-Like Behaviours and Regulates Apoptotic Signalling Induced by Olfactory Bulbectomy. Phytother Res 30(3): 469-475

117.Tao W, Wang H, Su Q, Chen Y, Xue W, et al. (2016) Paeonol attenuates lipopolysaccharide-induced depressive-like behavior in mice. Psychiatry Res 238: 116-121.

118.Zhu XL, Chen JJ, Han F, Chuan P, Zhuang TT, et al. (2018) Novel antidepressant effects of Paeonol alleviate neuronal injury with concomitant alterations in BDNF, Rac1 and RhoA levels in chronic unpredictable mild stress rats. Psychopharmacology (Berl) 235(7): 2177-2191.

119.Baune B T (2017) Are Non-steroidal Anti-Inflammatory Drugs Clinically Suitable for the Treatment of Symptoms in Depression-Associated Inflammation. Curr Top Behav Neurosci 31: 303-319.

120.Bai S, Guo W, Feng Y, Deng H, Li G, et al. (2020) Efficacy and safety of antiinflammatory agents for the treatment of major depressive disorder: a systematic review and meta-analysis of randomised controlled trials. J Neurol Neurosurg Psychiatry 91(1): 21-32

121.Kohler Forsberg O, Buttenschon H N, Tansey K E, Maier W, Hauser J, et al. (2017) Association between C-reactive protein (CRP) with depression symptom severity and specific depressive symptoms in major depression. Brain Behav Immun 62: 344-350.

122.Li J, Wang H, Du C, Jin X, Geng Y, et al. (2020) hUC-MSCs ameliorated CUMS-induced depression by modulating complement C3 signalingmediated microglial polarization during astrocyte-microglia crosstalk. Brain Res Bull 163: 109-119.

123.Zhao ZJ, Zhao C, Xiao J, Wang JC (2016) Transdermal Permeation and Anti-Inflammation Activities of Novel Sinomenine Derivatives. Molecules (Basel, Switzerland) 21(11).

124.Li X, Liu C, Jiang B, Chen K, Li W, et al. (2018) The antidepressantlike effects of sinomenine in mice: a behavioral and neurobiological characterization. Behav Pharmacol 29(4): 306-315.

125.Liu S, Xu S, Wang Z, Guo Y, Pan W, et al. (2018) Anti-Depressant-Like Effect of Sinomenine on Chronic Unpredictable Mild Stress-Induced Depression in a Mouse Model. Med Sci Monit 24: 7646-7653.

126.Fan J, Zhang K, Jin Y, Li B, Gao S, et al. (2019) Pharmacological effects of berberine on mood disorders. J Cell Mol Med 23(1): 21-28.

127.Liu YM, Niu L, Wang LL, Lia B, Xiao YF, et al. (2017) Berberine attenuates depressive-like behaviors by suppressing neuro-inflammation in stressed mice. Brain Res Bull 134: 220-227.

128.Gong Q Yan XJ, Lei F, Wang ML, He LL, et al. (2019) Proteomic profiling of the neurons in mice with depressive-like behavior induced by corticosterone and the regulation of berberine: Pivotal sites of oxidative phosphorylation. Mol Brain 12(1): 118.

129.Ren Z, Yan P, Zhu L, Huicui Y, Yafeiet Z, et al. (2018) Dihydromyricetin exerts a rapid antidepressant-like effect in association with enhancement of BDNF expression and inhibition of neuroinflammation. Psychopharmacology (Berl) 235(1): 233-244.
130.Guan S, Shen Y, Ge H, Wei Xiong, Lingkun He, et al. (2019) Dihydromyricetin Alleviates Diabetic Neuropathic Pain and Depression Comorbidity Symptoms by Inhibiting P2X Receptor. Front Psychiatry 10: 770 .

131.Jin J, Wang H, Hua X, Chen D, Huang C, et al. (2019) An outline for the pharmacological effect of icariin in the nervous system. Eur J Pharmacol 842: 20-32.

132.Liu B, Xu C, Wu X, F Liu, Y Du, et al. (2015) Icariin exerts an antidepressant effect in an unpredictable chronic mild stress model of depression in rats and is associated with the regulation of hippocampal neuroinflammation. Neuroscience 294: 193-205.

133.Liu L, Zhao Z, Lu L, Liu J, Sun J, et al. (2019) Icariin and icaritin ameliorated hippocampus neuroinflammation via mediating HMGB1 expression in social defeat model in mice. Int Immunopharmacol 75: 105799.

134.Zhang X, Sun H, Su Q, Qian Su, Tianwei Lin, et al. (2017) Antidepressantlike activity of icariin mediated by group I mGluRs in prenatally stressed offspring. Brain Dev 39(7): 593-600.

135.Nakazawa T, Yasuda T, Ueda J, Ohsawa K, (2003) Antidepressant-like effects of apigenin and 2,4,5-trimethoxycinnamic acid from Perilla frutescens in the forced swimming test. Biol Pharm Bull 26(4): 474-80.

136.Yi LT, Li JM, Li YC, Pan Y, Xu Q et al. (2008) Antidepressant-like behavioral and neurochemical effects of the citrus-associated chemical apigenin. Life Sci 82(13-14): 741-51.

137.Li R, Wang X, Qin T, Qu R, Ma S, et al. (2016) Apigenin ameliorates chronic mild stress-induced depressive behavior by inhibiting interleukin-1 $\beta$ production and NLRP3 inflammasome activation in the rat brain. Behav Brain Res 296: 318-325.

138.Sundarraj K, Raghunath A, Perumal E (2018) A review on the chemotherapeutic potential of fisetin: In vitro evidences. Biomedicine \& pharmacotherapy = Biomedecine \& pharmacotherapie 97: 928-940.

139.Zhen L, Zhu J, Zhao X, Yiran An, Shan Li, et al. (2012) The antidepressantlike effect of fisetin involves the serotonergic and noradrenergic system. Behav Brain Res 228(2): 359-366.

140.Yu X, Jiang X, Zhang X, Ziwei Chen, Lexing Xu, et al. (2016) The effects of fisetin on lipopolysaccharide-induced depressive-like behavior in mice. Metab Brain Dis 31(5): 1011-1021.

141.Maepa M, Razwinani M, Motaung S, (2016) Effects of resveratrol on collagen type II protein in the superficial and middle zone chondrocytes of porcine articular cartilage. J Ethnopharmacol 178: 25-33.

142.Fahim AT, Abd El-Fattah AA, Sadik N, Ali BM (2019) Resveratrol and dimethyl fumarate ameliorate testicular dysfunction caused by chronic unpredictable mild stress-induced depression in rats. Arch Biochem Biophys 665: 152-165.

143.Abd El-Fattah AA, Fahim AT, Sadik N, Ali BM (2018) Resveratrol and dimethyl fumarate ameliorate depression-like behaviour in a rat model of chronic unpredictable mild stress. Brain Res 1701: 227-236.

144.Hurley LL, Akinfiresoye L, Kalejaiye 0, Tizabi Y (2014) Antidepressant effects of resveratrol in an animal model of depression. Behav Brain Re 268: 1-7.

145.Sulakhiya K, Keshavlal GP, Bezbaruah BB, Dwivedi S, Gurjar SS, et al. (2016) Lipopolysaccharide induced anxiety- and depressive-like behaviour in mice are prevented by chronic pre-treatment of esculetin. Neurosci Lett 611: 106-111.

146.Zhu L, Nang C, Luo F, Hong Pan, Kai Zhang, et al. (2016) Esculetin attenuates lipopolysaccharide (LPS)-induced neuroinflammatory processes and depressive-like behavior in mice. Physiol Behav 163: 184-192. 
147.Zhang L, Previn R, Lu L, Liao RF, Jin Y, et al. (2018) Crocin, a natural product attenuates lipopolysaccharide-induced anxiety and depressivelike behaviors through suppressing NF-kB and NLRP3 signaling pathway. Brain Res Bull 142: 352-359.

148.Xiao Q, Xiong Z, Yu C, Zhou J, Shen Q et al. (2019) Antidepressant activity of crocin-I is associated with amelioration of neuroinflammation and attenuates oxidative damage induced by corticosterone in mice. Physiol Behav 212: 112699.

149.Rossi M, Lugo A, Lagiou P, J Polesel, D Serraino, et al. (2012) Proanthocyanidins and other flavonoids in relation to pancreatic cancer: a case-control study in Italy. Ann Oncol 23(6): 1488-93.

150.Jiang X, Liu J, Lin Q, Kaili Mao, Furong Tian, et al. (2017) Proanthocyanidin prevents lipopolysaccharide-induced depressive-like behavior in mice via neuroinflammatory pathway. Brain Res Bull 135: 40-46.

151.Schatzberg AF (2015) Anna-Monika Award Lecture, DGPPN Kongress, 2013: The role of the hypothalamic-pituitary-adrenal (HPA) axis in the

ISSN: 2574-1241

DOI: 10.26717/BJSTR.2021.40.006446

WANG Yuhong, LI Shunxiang. Biomed J Sci \& Tech Res

(C) This work is licensed under Creative

Submission Link: https://biomedres.us/submit-manuscript.php pathogenesis of psychotic major depression. World J Biol Psychiatry 16(1): 2-11.

152.Hodez GE, Kana V, Menard C, Merad M, Russo SJ, et al. (2015) Neuroimmune mechanisms of depression. Nat Neurosci 18(10): 13861393.

153.Egeland M, Zunszain PA, Pariante CM (2015) Molecular mechanisms in the regulation of adult neurogenesis during stress. Nat Rev Neurosci 16(4): 189-200.

154.Nabavi SM, Nabavi SF, Eslami S, Moghaddam AH (2012) In vivo protective effects of quercetin against sodium fluoride-induced oxidative stress in the hepatic tissue. Food Chem 132(2): 931-935.

155.Alinezhad H, Azimi R, Zare M, Ebrahimzadeh MA, Nabavi SM, et al. (2011) Antioxidant and Antihemolytic Activities of Ethanolic Extract of Flowers, Leaves, and Stems of Hyssopus officinalis L Var. angustifolius. International Journal of Food Properties 16(5): 1169-1178.

$\begin{array}{ll}\text { BIOMEDICAL } & \text { Assets of Publishing with us } \\ \text { RESEARCHES } & \text { - Global archiving of articles } \\ \text { - Immediate, unrestricted online access }\end{array}$

